DOI: 10.17707/AgricultForest.64.1.13

\begin{abstract}
Natalia YEGOROVA, Valentina BRAILKO, Irina STAVTZEVA, Irina MITROFANOVA ${ }^{1}$
\end{abstract}

\title{
SOME MORPHOPHYSIOLOGICAL FEATURES OF LAVANDER CULTIVAR MICROPROPAGATED IN VITRO BY MERISTEM CULTURE
}

\begin{abstract}
SUMMARY
The data about some morpho-physiological peculiarities of explants of lavender (Lavandula angustifolia Mill.) the cultivars Stepnaya, Sineva, Vdala, Record, Rannyaya, introduced by meristems in aseptic conditions and under long-term micropropagation in vitro are presented. During cultured meristems on Murashige and Skoog (MS) medium with $1.0 \mathrm{mg} \mathrm{L}^{-1}$ Kinetin and $0.5 \mathrm{mg} \mathrm{L}^{-1} \mathrm{GA}_{3}$ all cultivars have formed the multiple shoot. The maximum number of microshoots at in vitro introduction stage was in the cultivar Sineva (5.7), and minimum - in the cultivar Rannyaya (3.9). Further, microcutting of main and additional shoots was conducted every 30-35 days. Obtained shoot segments with one node on MS medium with $1.0 \mathrm{mg} \mathrm{L}^{-1}$ Kinetin and $0.5 \mathrm{mg} \mathrm{L}^{-1} \mathrm{GA}_{3}$ were cultured. When micropropagation of lavender follow $6^{\text {th }}$ subculture it was shown that the number of shoots was increased in all cultivars till 3 subculture, and then it was decreased. In the cultivar Sineva the maximal multiplication index (12.2) was noted at the third passage, and then changed from 11.5 to 7.4 . The lowest multiplication index at 5-7 $7^{\text {th }}$ passages was in the cultivar Record (3.8-4.5). Analysis of water regime of obtained microshoots at $6^{\text {th }}$ subculture showed that the total water content was $83-89 \%$, and the fraction of bound and colloidabsorbed water was $40-57 \%$. Maximum values of water-holding capacity in the cultivars Record, Rannyaya and Vdala were found. Studying the parameters of light-induction processes it has been showed that the cultivars Vdala and Sineva were characterized by maximum photosynthetic activity of leaves and shoots, and they had high viability index.
\end{abstract}

Keywords: Lavandula angustifolia, clonal micropropagation, multiplication index, water regime, photosynthetic activity.

\footnotetext{
${ }^{1}$ Natalia Yegorova (corresponding author: yegorova.na@mail.ru), Federal State-Funded Institution of Science "The Labour Red Banner Order Nikita Botanical Gardens - National Scientific Center of RAS", Nikita, RUSSIA, Federal State-Funded Institution of Science «Research Institute of Agriculture of the Crimea», Simferopol, Crimea, Valentina Brailko, Federal State-Funded Institution of Science "The Labour Red Banner Order Nikita Botanical Gardens - National Scientific Center of RAS", Nikita, RUSSIA, Irina Stavtzeva, Federal State-Funded Institution of Science «Research Institute of Agriculture of the Crimea», Simferopol, Crimea, Irina Mitrofanova, Federal State-Funded Institution of Science "The Labour Red Banner Order Nikita Botanical Gardens - National Scientific Center of RAS", Nikita, RUSSIA

Paper presented at the $8^{\text {th }}$ International Scientific Agricultural Symposium "AGROSYM 2017".

Notes: The authors declare that they have no conflicts of interest. Authorship Form signed online.
} 


\section{INTRODUCTION}

Lavender is one of the most widely spread essential oil, medicinal and spicy aromatic plants, which is grown in many countries of the world. In Russia and the southern regions of Europe is predominantly cultivated Lavandula angustifolia Mill., less often - L. latifolia Vill., L. stoechas L. and lavandin (Lavandula $x$ intermedia Emeric ex Loisel) (Bochkarev and Zelentsov, 2013). Plant raw material of lavender contains essential oil and complex phenolic compounds, such as flavones, anthocyanins (Harborne and Williams, 2002). Lavender essential oil, the main components of which are linalyl acetate, linalool and geraniol, is used in the perfumery, cosmetics and food industries, in ceramic and paint production. It is used in medicine as wound healing, antispasmodic and sedative agent. Lavender is also successfully used as ornamental, honey and antierosion plant, cultivated on sloping lands.

Traditional methods of lavender vegetative propagation (woody or green stem cutting) do not allow to obtain high quality planting material with a high multiplication index, that can be overcome by micropropagation in vitro. There are data on some aspects of clonal micropropagation of L . officinalis (Chishti et al., 2006), L. dentata (Bona et al., 2011), L. angustifolia (Hamza et al., 2011, Yegorova, 2008), L. viridis (Dias et al., 2002), L. vera (Andrade et al., 1999), L. pedunculata (Zuzarte et al., 2010), lavandin (Lucchesini et al., 2006, Mitrofanova et al., 2016) and other lavender species. Most of these studies were devoted to optimization of culture media composition for growth of microshoots and their rooting. The best development of microshoots in L. viridis was achieved when explants cultured on the medium with BAP (Dias et al., 2002), in L. dentate BAP and IBA (Echeverrigaray et al., 2005), in L. officinalis - BAP and IAA (Chishti et al., 2006), in L. angustifolia - TDZ (Hamza et al., 2011) or Kinetin and $\mathrm{GA}_{3}$ (Yegorova, 2008). In some studies it is analyzed the influence on the efficiency of micropropagation a species or cultivars (Bona et al., 2011, Yegorova and Stavtzeva 2015), type of explant (Bona et al., 2011, Hamza et al., 2011). Biochemical and physiological features during lavender and lavandine cultivars clonal micropropagation were revealed and adaptive capacity of this

two essential oil species was investigated (Mitrofanova et al., 2016, Grebennikova et al., 2017). However, many questions concerning propagation in vitro, especially during long-term subculture, while insufficiently were studied.

The aim of this work was to study the morphometric and physiological parameters of explant development in five L. angustifolia cultivars under longterm micropropagation in vitro.

\section{MATERIAL AND METHODS}

Five cultivars of lavender (Lavandula angustifolia Mill.) - Stepnaya, Sineva, Rannyaya, Vdala, Record were investigated. The initial plants were grown in field condition of Crimea foothill zone. As a primary explants meristems with one pair of leaf primordia from axillary buds were used. For micropropagation the segments of the stem with a node $(5-7 \mathrm{~mm})$, obtained by 
microcutting of microshoots were used. Meristems were cultivated on the modified Murashige and Skoog (MS) medium with $1.0 \mathrm{mg} \mathrm{L}^{-1}$ Kinetin and 0.5 $\mathrm{mg} \mathrm{L}^{-1} \mathrm{GA}_{3}$, microcuttings - with $0.5 \mathrm{mg} \mathrm{L}^{-1}$ Kinetin and $0.1 \mathrm{mg} \mathrm{L}^{-1} \mathrm{GA}_{3}$ (Yegorova, 2008). Explants in test tubes were kept at $24-26^{\circ} \mathrm{C}, 70 \%$ of relative air humidity, under 16-h photoperiod with illumination 2-3 klx. Microcuttings was conducted every 30-35 days, before which the length and number of shoots, the number of nodes (pairs of leaves) on shoot, the frequency of multiple shoot formation, callusogenesis and rhizogenesis were determined. The multiplication index was calculated as the number of microcuttings that can be obtained during one subculture. For this the number of formed on the explant shoots was multiplied on the number of nodes on the shoot. Experiments on in vitro culture were carried out in three replications; at each variant 20 explants were analyzed.

The total water content in leaves and its fractional composition were studied and analyzed (Lishchuk, 1991) as physiological criteria characterizing the water regime in plants. The parameters of photosynthetic activity were measured using a portable fluorometer LPT-1/CFU (Russia), which had been designed to assess the functional state of photosynthetic apparatus in various plant organs and tissues in vitro according to the parameters of chlorophyll fluorescence induction. In the device fluorescence is excited in the blue spectral region $(470 \mathrm{~nm})$, the Kautsky curve is detected, and on its basis indexes of the light energy photosynthetic transformation in the plant cell are determined. During the experiments we recorded such components of fluorescence induction kinetics as initial fluorescence level $\left(\mathrm{F}_{0}\right)$, maximum $\left(\mathrm{F}_{\mathrm{m}}\right)$ and stationary $\left(\mathrm{F}_{\mathrm{st}}\right)$ fluorescence after the light adaptation. Based on the data obtained, the viability index and photosynthetic activity were calculated (Korneev, 2002, Budagovsky et al., 2002) that allows to evaluate the functional state of photosynthetic tissues and the whole organism (Budagovsky et al., 2002). The experiments were performed in 3 biological and 3 analytical replications. For statistic description of experimental results methods of statistical analyses were used (STATISTICA 6.0 Software).

\section{RESULTS AND DISCUSSION}

When isolated meristems of lavender cultivars have been introduced into in vitro culture, the development of main microshoot was started in a week of cultivation. Two weeks later, adventive buds were appeared, from which shoots were regenerated. The frequency of multiple shoot formation in all cultivars was quite high and reached a maximum in the cultivar Sineva (94.1\%). The number of microshoots depended on the genotype and varied from 3.9 (the cultivar Rannyaya) to 5.7 pcs / explant (the cultivar Sineva). At the stage of the meristems in vitro introduction, in addition to the development of shoots, the formation of 1-2 small roots with a frequency of up to $12.5 \%$ was observed in the cultivars Vdala and Record. At the base of microshoots with frequency of 6.5$17.8 \%$ in the cultivars Rannyaya and Vdala a small dense callus was developed. It should be noted that the induction of callusogenesis is undesirable during micropropagation because the probability of somaclonal variants occurrence, 
therefore the emerging callus was removed by subculturing. Some authors when cultured lavender buds or nodal segments also revealed callus formation (Dias et al., 2002, Zuzarte et al., 2010, Bona et al., 2011).

Shoots, obtained from meristems in vitro, for further micropropagation were divided into single-node microcuttings and transferred on Murashige and Skoog medium with Kinetin and $\mathrm{GA}_{3}$. At this stage (micropropagation proper), one or two shoots (up to 20-30 mm long with 4-5 nodes) from the axillary buds of the microcuttings and up to 6-10 additional shoots were developed. On average, from the microcutting, depending on the cultivar and number of subcultures, were developed from 1.6 to 3.5 shoots with 1.9-3.6 pairs of leaves (nodes). Our results indicate the possibility of using several methods for lavender multiplication - microshoots cutting, induction of axillary and adventitious shoots. This allows to increase the multiplication index. In studied cultivars at this stage the rare cases of callus or root formation, as well as development of hyperhydrated shoots, were noted. The exception was the cultivar Sineva, which formed the greatest number of shoots, some of them showed signs of vitrification. In some studies, concerning the lavender micropropagation, the formation of hyperhydrated shoots also have been shown. Frequency of such shoots regeneration depended on the concentration of growth regulators (Andrade et al., 1999) or agar (Lucchesini et al., 2006). Hamza et al. (2011) noted that in $L$. angustifolia the frequency of vitrification was reduced with increasing sucrose content and under using 1/2-1/4 strength culture medium.

An important question at the second stage of micropropagation is the study of influence of subcultures number on the development of meristem cultures. This is necessary to obtain a multiply microplants during long time. Study of the lavender micropropagation during six subcultures showed the variability of some morphometric parameters and the multiplication index, which are depended on the duration of cultivation. By third passage the number of shoots and the number of its nodes were increased, which led to increase the multiplication index in all studied cultivars (Figure 1). The highest multiplication index had the cultivars Sineva and Rannyaya. After that, at $5-6^{\text {th }}$ subcultures a decrease of the multiplication index (almost to the level of the first passage) and the stabilization of this parameter were observed. The most active regeneration of adventitious shoots was noted in the cultivar Sineva, which had the maximum multiplication index (up to 12.2).

The cultivars Vdala and Rannyaya in the $3-4^{\text {th }}$ passages also showed a high micropropagation capacity. It should be noted that, in contrast to other studied cultivars, in the cultivar Sineva the multiplication index at $5-6^{\text {th }}$ subculture was significantly higher than in the first one. The obtained data indicate the possibility of prolonged clonal micropropagation of $L$. angustifolia cultivars in vitro. When analyzing the effect of the duration of culture on the micropropagation of certain essential oil plants, it was found that in geranium the multiplication index during two years have not changed. At the same time in sage and fennel during the first three passages the multiplication index have not 
changed significantly, and then gradually have decreased (Yegorova et al., 2013). The study of essential oil rose cultivars during 9 subculture shown the increase of multiplication index at $3-4^{\text {th }}$ passages (Yegorova et al., 2015).

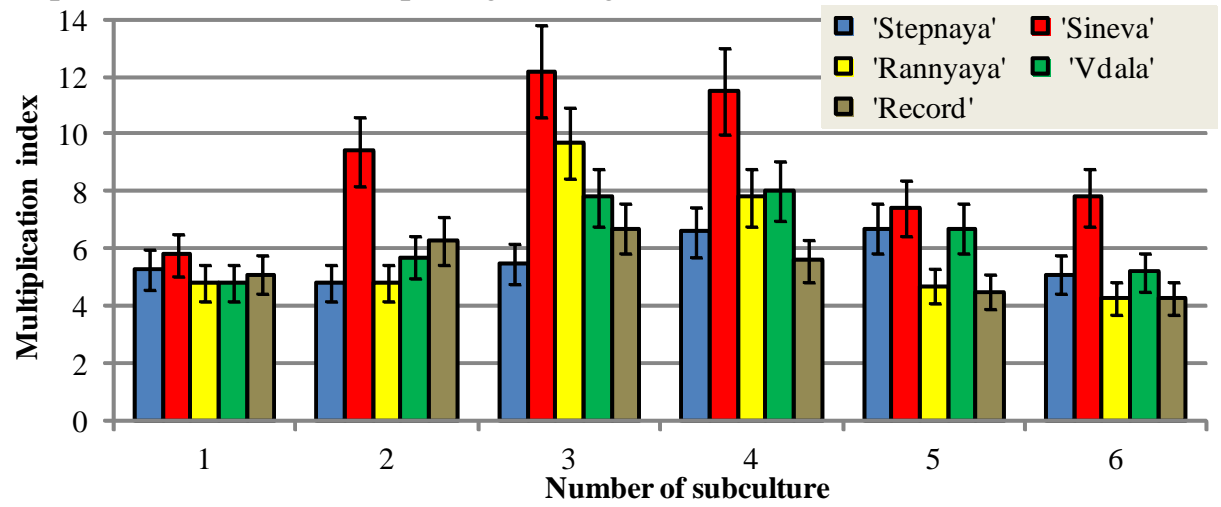

Figure 1. Influence of subculture number and cultivar on the lavender in vitro multiplication index

The ability to regulate water regime under aseptic conditions is one of the characteristics of their high adaptive capacity in the subsequent stages of in vivo and ex situ cultivation. Seeing some xeromorphic features in the organization of L. angustifolia vegetative organs ex situ (Rabotyagov et al., 2014) and in vitro (Brailko et al., 2017), we suppose the presence of genetic potential for the implementation of water stress protective mechanisms at all stages of biotechnology process of micropropagation.

Microshoots of different cultivars obtained in vitro at the sixth subculture were used for physiological investigations. Lavender cultivars studied in vitro were highly watered, the total water content was $83-89 \%$. Wherein, there were no significant differences among the studied cultivars on this parameter. The part of bound water was $40-57 \%$ of the total water content. The maximum osmotic and colloid-bound water was noticed in the cultivars Record (56.65\%), Rannyaya (54.51\%) and Vdala (47.64\%). The data obtained are corresponded with the results of previous studies in some L. angustifolia and L. hybrida Rev. cultivars carried out during the first passage (2 months) on the modified MS medium with $0.3 \mathrm{mg} \mathrm{L}^{-1}$ Kinetin, $0.025 \mathrm{mg} \mathrm{L}^{-1} \mathrm{NAA}$ and $0.25 \mathrm{mg} \mathrm{L}^{-1} \mathrm{GA}_{3}$ (Brailko et al., 2017; Mitrofanova et al., 2016).

Studies of the structural rearrangements dynamics in living objects are a promising but very complex problem in experimental biology. Especially relevant is the use of non-invasive methods for recording activity of the photosynthesis process, which allows the cultivars to remain vital and continue to monitor their functional state continuously. Some indexes of lavender assimilation capacity in vitro were investigated. The revealed features of lightinduction processes indicated a high photosynthetic activity in leaves and shoots of regenerants. Thus, the relative photosynthetic activity $\left(\mathrm{F}_{\mathrm{m}}-\mathrm{F}_{\mathrm{st}}\right) / \mathrm{F}_{\mathrm{m}}$ varied from 
$0.51 \pm 0.04$ to $0.68 \pm 0.04$ a.u. However, the cultivars Vdala and Sineva were characterized with the maximum values of this index, and in the cultivar Rannyaya it was minimal. Viability index $\left(\mathrm{F}_{\mathrm{m}} / \mathrm{F}_{\mathrm{st}}\right)$ was $1.38-2.71$ and it was maximum in the cultivars Vdala $(2.71 \pm 0.05)$ and Sineva $(2.56 \pm 0.18)$. In the cultivar Stepnaya we noticed minor abnormalities in the functioning of lightharvesting complexes: a significant part of the light energy was reflected, the maximum fluorescence was 117 a.u. Markers of lavender microshoots functional state determined by the method of chlorophyll fluorescence induction demonstrated the absence of photoinhibition and normal functioning of photosystems both at the level of light-harvesting complexes (the exception was the cultivar Stepnaya) and at the moment of electron donors oxidation in the photosystem II reaction center.

\section{CONCLUSIONS}

The morphophysiological peculiarities of explants in the process of 6 subcultures in micropropagation of five lavender cultivars have been identified. An increase of the multiplication index by third subculture was shown. The maximum ability for adventitious shoot formation and a high multiplication index was found in the cultivar Sineva.

Significant water retention capacity due to the bound water fraction was found under the high values of the total water content in leaf tissues of microshoots. Normal functional state of assimilating tissues in microshoots was demonstrated. The high photosynthetic activity of the leaves and the viability of the cultivars Vdala and Sineva have been identified, which corresponds to their best regenerative capacity during prolonged microcutting and a higher multiplication index. This is especially true for the cultivar Sineva, which was distinguished among the studied genotypes, both during the stage of meristem introducing and during six subcultures in vitro.

\section{ACKNOWLEDGEMENT}

This study was funded by a research grant № 14-50-00079 of the Russian Science Foundation.

\section{REFERENCES}

Andrade L.B, Echeverrigaray S., Fracaro F., Pauletti G.F., Rota L. (1999). The effect of growth regulators on shoot propagation and rooting of common lavander (Lavandula vera DC). Plant Cell Tissue Org. Cult., 56 (2), P. 79-83.

Bochkarev N.I., Zelentsov S.V. (2013). The current state of taxonomy, morphology and breeding of lavender. Oilseeds. Scientific and technical bulletin VNIIMK, 155156 (2), P.163-178. [In Russian]

Bona C.M., Reinhart V., Biasi L.A., Zanette F. (2011). Lavandula dentate and Lavandula angustifolia in vitro organogenesis. Plant Cell Cult. Micropropag., 7 (2), P. 66-70.

Brailko V.A., Mitrofanova O.V. Lesnikova-Sedoshenko N.P., Chelombit S.V., Mitrofanova I.V. (2017). Anatomy features of Lavandula angustifolia Mill. and Lavandula hybrida Rev. plants in vitro. Agriculture \& Forestry, 63 (1), P. 111117. 
Budagovsky A., Budagovskaya O., Lenz F., Keutgen A., Alkayed K. (2002). Analysis of functional state of cultivated plants by means of interference of scattered light and chlorophyll fluorescence. Journal of Applied Botany, 76, P. 115-120.

Chishti N., Kaloo Z.A., Shawl A.S., Sultan Ph. (2006). Rapid in vitro clonal propagation of Lavandula officinalis chaix a multipurpose plant of industrial impotance. Pakistan J. Biol. Sciences, 9, P. 514-518.

Dias M.C., Almeida R., Romano A. (2002). Rapid clonal multiplication of Lavandula viridis L’Her through in vitro axillary shoot proliferation. Plant Cell Tissue Org. Cult, 68 (1), P. 99-102.

Echeverrigaray S., Basso R., Andrade L.B. (2005). Micropropagation of Lavandula dentata from axillary buds of field-grown adult plants. Biol. Plantarum, 49 (3), P. 439-442.

Grebennikova O., Paliy A., Brailko V., Mitrofanova O., Rabotyagov V., Zhdanova I., Mitrofanova I. (2017). Adaptive capacity of some lavender and lavandin cultivars in vitro and in situ. AGROFOR International Journal, 2 (1), P. 91-98.

Hamza A.M., Abd El-Kafie Omaima M., Kasem M.M. (2011). Direct micropropagation of English lavender (Lavandula angustifolia Munstead) plant. J. Plant Production Mansoura Univ., 2 (1), P. 81-96.

Harborne J.B., Williams C. (2002). Phytochemistry of the genus Lavandula. in M. LisBalchin (ed.). Lavender. The genus Lavandula: Medicinal and Aromatic Plants Industrial Profiles, Taylor and Francis, London, P. 86-99.

Korneev D.Yu. (2002). Information possibilities of the method of chlorophyll fluorescence induction, Alytenpress, Kiev, 188 p. [In Russian]

Lishchuk A.I. (1991) A technique for determining the water retention capacity for dehydration of fruit leaves. Physiological and biophysical methods in the selection of fruit crops: methodological recommendations, GNBS, Moscow, P. 33-36. [In Russian]

Lucchesini M., Pacifici S., Tognoni F., Mensuali-Sodi A., Serra G. (2006). Optimisation of in vitro cultural conditions of some officinal species. Acta Hort., 723, P. 6-10.

Mitrofanova O.V., Grebennikova O.A., Paliy A.E., Brailko V.A., Mitrofanova I.V. (2016). Biochemical and physiological features of regenerants in some lavender and lavandin cultivars in vitro. Plant Cell Biotechnology and Molecular Biology, 17 (7-8), P. 335-341.

Rabotyagov V.D., Svidenko L.V., Boyko M.F. (2014) Anatomical and morphological features of interspecific F1 hybrids in comparison with the original diploid species and tetraploid. Chornomors'k. bot.z., 10 (1), 127-137. [In Russian]

Yegorova N.A. (2008). Obtaining of plant-regenerants in callus culture and micropropagation in vitro of lavender (methodical recommendations), Simferopol, IELR UAAN, 28 p. [In Russian]

Yegorova N.A., Krivokhatko A.G., Stavtzeva I.V., Kamenek L.I. (2013). Micropropagation of essential oil plants using the culture of isolated tissues and organs in vitro. Taurida herald of the agrarian science, 1 (1), P.9-14. [In Russian]

Yegorova N.A., Stavtzeva I.V. (2015) Development of biotechnological methods of micropropagation in vitro for Lavandula angustifolia Mill. Proceedings of the Kuban State Agrarian University, 54 (3), P.138-142. [In Russian]

Yegorova N.A., Stavtzeva I.V., Mitrofanova I.V. (2016). Influence of cultivar and cultivation factors in vitro on the essential oil rose clonal micropropagation. Proceedings of the Nikit. Botan. Gard., 120, P. 36-43. [In Russian]

Zuzarte M.R., Dinis A.M., Cavaleiro C., Salgueiro L.R., Canhoto J.M. (2010). Trichomes, essential oils and in vitro propagation of Lavandula pedunculata (Lamiaceae). Industrial Crops and Products, 32, P. 580-587. 